\title{
Effectiveness of Group Problem Solving Education on Social and Resilient Skills in Twelve High School Grade Girls in Seventh District of Tehran
}

\author{
Shima Darvish \\ Azad University Central Branch, Tehran, Iran
}

\begin{abstract}
The purpose of this study was to investigate Effectiveness of Group Problem Solving Education on Social and Resilient Skills in Twelve High School Grade Girls in Seventh District of Tehran. The research method was applied due to the objectives of the study, and according to the method of data collection, a quasi-experimental research type was chosen. A statistical population including Twelve High School Grade in Tehran during the academic year of 2007-2013. They were selected using a multi-stage random sampling of 30 students (15 control group and 15 experimental group) to research and respond to Gersham and Elliot questionnaire (1999) and the perseverance of Connor and Davidson (2003). For analyzing the findings, descriptive and inferential statistical methods such as covariance analysis test were used. The research findings indicated a significant difference between the mean scores of social skills and their dimensions - cooperation, self-esteem, and assertiveness - in the groups of both experimental and control groups. Also, there is a significant difference between the mean resiliency scores and their dimensions - individual sense of ability, resistance to negative effects, positive acceptance of change, trust in individual instincts, sense of support and social security, spiritual faith and pragmatic approach to problem solving methods - in two groups were obtained. In other words, group problem solving training has affected social skills and resilience of students.
\end{abstract}

Keywords: group problem solving, social skills, resilience, students.

DOI: $10.7176 / \mathrm{RHSS} / 9-10-10$

Publication date:May $31^{\text {st }} 2019$

\section{Introduction}

Adolescence is one of the most important and most sensitive periods in human life and has its own effects and symptoms. Ern introduces this stage of life as a period of rapid growth and rapid change that includes important consequences such as the presence of high-risk behaviors. According to the research conducted by Miller \& Chestnak, the incidence of high-risk behaviors among adolescents and young people is higher than other members of the community. Rutter believes that preventing this problem requires identifying risk factors and protecting against high-risk behaviors. Some researchers believe that adolescent tendencies to high-risk behaviors are a reflection of emotional and psychological problems that they face. Teenagers are involved with high-risk behaviors that make them vulnerable. Research has also shown that many adolescents who live in highrisk environments and conditions that expose them to various physical and psychological hazards, however, due to protective factors such as high resilience to stress, Have been able to overcome these problems and become invulnerable (Soleimanian, 1392).

In recent years, the positive psychology approach, with the emphasis on human talents and abilities, has been considered by researchers from different fields of psychology. This approach, its end goal, identifies the structures and methods that provide human well-being and happiness. Hence, the factors that cause more human adaptation to the needs and threats of life are the most fundamental structures under study in this approach. Meanwhile, resilience has a special place, especially in the areas of transformational psychology, family psychology and mental health (Campbell Sylves, Cohen and Stein, 2006, quoted by Jokar, 2007).

In the past, there have been various researches about the factors associated with social skills and its impact on the problem that group problem solving is one of the factors that affects social skills and viability. Given the sociality of humans and the need for them to interact with others, to meet the emotional, social, and biological needs, we need to familiarize with the number and complexity of the rules that we must know to interact with others and use them correctly (Soleimani , 1390).

Regarding the lack of access to a research similar to the current research, this research seeks to answer the question whether the problem solving training affects the social skills and resilience of undergraduate preuniversity girls in Tehran.

\section{Research Methodology}

The present study is aimed at applying applied research. The purpose of applied research is the development of applied knowledge in a particular field (Hooman, 1395). This research seeks to investigate the effectiveness of group problem solving training on social and resilient skills in pre-university students. Upon completion of the 
research, its applicability in the studied population is also considered to be due to data collection. Quasiexperimental research. A quasi-experimental research is a research that allows the manipulation of an independent variable, and we create the conditions that affect the independent variable on the dependent variable (Hooman, 1395).

\section{Statistical community of the research}

The statistical population is a set of individuals or units that have at least one commonality (Hooman, 1395). Considering the definition of the statistical society, all students of pre-university girls of logic of 7 cities of Tehran are present.

\section{3-3 Sampling and sampling method}

In order to select the sample, according to the number of population, using multi-stage random sampling method, 30 students (15 in control group and 15 in experimental group) ) Was confirmed. For this purpose, first of all, different regions of Tehran (22 areas of Tehran), region 7 were selected as the sample and in this area a school (non-profit Somayeh) was considered as a sample. Out of this school and various pre-university classes, 30 were selected as research sample.

\section{Tools for collecting information}

\section{3-4-1. Social skills questionnaire}

In this research, Gersham and Elliot (1999) Social Skills Scale were used to measure social skills. In this research, three components were used: cooperation (items 1 to 10), decisiveness (items 11 to 16), and selfesteem (items 17 to 23). The reliability of Gersham and Elliott scale (1999) has been investigated and confirmed in various studies. For example, Gresham and Elliot (1999) consider the internal-level reliability of the scale for teachers to be between 0.44 and 0.96 . Shahim (2002) in a study in Iran examined the social skills of mentally retarded children using this scale. The reliability of this scale in his study for social skills was $0.87,0.76,0.74$, 0.74 , and 0.88 , respectively. In this research, Cronbach's alpha coefficient was used to determine the reliability of the questionnaire. In the next step, the implementation of each questionnaire questionnaire was presented with its components (Khoshkam et al., 2008).

Table 1-3: Matching the Questions of the Social Skills Questionnaire Gersham and Eliot (1999) (Joshkam et al., 2008).

\begin{tabular}{rrrr}
\hline Questions per subscale & Subscales & Questions for any scale & Scale \\
\hline $1-10$ & Cooperation & Questions 1 to 23 & social skills \\
$11-16$ & Assertive & & \\
$17-23$ & Continence & & \\
\hline
\end{tabular}

\section{3-4-2- Resonance questionnaire}

The questionnaire was prepared by Conner and Davidson (2003) by reviewing the research resources of 19791991. The psychometric features of this scale were evaluated in six groups: general population, referrals to primary care, outpatient psychiatric patients, patients with generalized anxiety disorder, and two groups of posttraumatic stress disorder patients. Producers of this scale believe that this questionnaire is well able to distinguish people from non-susceptible patients in clinical and non-clinical groups and can be used in clinical and clinical settings. Quoted by Mohammadi, 1384). This scale has 25 options in five. This scale is standardized in Iran by Mohammadi (2005). They reported the reliability of the scale by 0.89 Cronbach's alpha. The dimensions of the resiliency questionnaire include (sense of individual ability, resistance to negative effects, positive acceptance of change, trust in individual instincts, sense of support and social security, spiritual faith, and pragmatic approach to problem solving methods).

Table 2-2: Matching Questions of Researcher Questionnaire Conner \& Davidson (2003) (Mohammadi, 2005)

\begin{tabular}{|c|c|c|c|}
\hline $\begin{array}{r}\text { per } \\
\text { subscale }\end{array}$ & Subscales & $\begin{array}{l}\text { Questions for any } \\
\text { scale }\end{array}$ & Scale \\
\hline $4,6,7,10,11,12$ & Sense of individual ability & \multirow{7}{*}{ Questions 1 to 25} & \multirow{7}{*}{ Resilient } \\
\hline $8,19,20,21$ & Resistance to negative effects & & \\
\hline $14,15,16,22$ & Accept positive change & & \\
\hline $9,13,23$ & Trust in individual instincts & & \\
\hline 18,25 & Sense of support and social security & & \\
\hline $3,5,7$ & Spiritual Faith & & \\
\hline $1,2,24$ & $\begin{array}{l}\text { Pragmatic approach to problem } \\
\text { solving }\end{array}$ & & \\
\hline
\end{tabular}




\section{3-4-3-Grouping problem solving training protocol}

The problem solving training process consists of six steps in problem design, information gathering, precise problem definition, hypothesis making, hypothesis testing, and implementation and evaluation. The following describes each step.

1) Problem design or problem representation: The problem can be created in different ways in students' minds. Prior to the design of the problem, one should pay attention to the characteristics of learners such as age, level of education, mental and emotional development, and cultural characteristics, social and economic conditions. In other words, the stage of identification or problem design is the stage in which the mind (thought or feeling) faces a problem or problem.

2) Information gathering: In order for a problem or problem to be clearly identified, it is necessary to collect accurate information about that subject. Of course, the sources of data collection are scientifically valid and the information collected should be categorized according to the correct criteria.

3) The exact definition of the problem: At this stage, the person finds out the problem and the nature of the problem by examining the information collected.

4) Making a Hypothesis: A hypothesis is a conjecture formed on the basis of past information and existing evidence in dealing with the outside world in the student's mind. Therefore, the purpose of hypothesis is to predict probable and hypothetical solutions to the problem. . The student has to think in order to construct the hypothesis. To solve the problem, the student opts for several ways and creates and creates various solutions and tries to solve various solutions through intellectual precipitation, interaction and has gotten one with others. Write down all the different solutions that come into your mind. At this stage, the goal is just to find various solutions, not which of the selected choices is better and more acceptable.

5) Hypothesis Test: At this stage, the person will evaluate each of the solutions described in the previous step with a valuation score to find out which of the solutions has better performance and feasibility, and An earlier and better type can solve a problem or problem. In this stage, the goal is to judge and judge, in contrast to the previous stage, and to review the quality and content of the proposed solution and to implement it.

6) Implementation and evaluation: After selecting the best solution and its implementation, the evaluation of the problem or problem begins. If the chosen solution is successful, the problem ends. If it does not succeed, the next priority will be implemented. If one fails to solve the problem by solving the proposed solutions, it is possible that the problem is not accurately defined, so it is advisable to start and continue the steps from the exact definition of the problem.

\section{3-5. Method of research implementation}

A sample of the Department of Education in Tehran District 7 was referred to the selected school. After consultation with the director from different pre-university levels, 30 were selected as the sample. The sample group was first familiarized with the specialist and the researcher's goals in general and invited to collaborate in the research. Those who were prepared to prepare for the research were sent to the hall for conducting a group of tests. The questionnaires were filled out with descriptions of the necessary materials and collected. Subsequently, the experimental group was trained in 10 sessions of 2 consecutive weeks in 10 consecutive weeks. Interventions for problem solving skills Were the following schemes. Finally, the questionnaires were returned to both groups and the questionnaire was collected by the statistician to analyze the data.

\section{3-5-1-Method of implementing the educational protocol Problem-solving problem:}

Educational sessions were based on intellectual rainfall, providing feedback, designing half-finished stories and solving hypothetical problems. At the end of each session, assignments were given to students who at the next session reviewed the assignments and gave feedback to the students.

Session 1: Referrals and acquaintance with group members, group regulation, orientation, and the need for problem solving skills training.

Session 2: Brief introduction of "problem solving skills" and its importance in social relationships with active discussion in the classroom, familiarity with concepts related to problem solving and carrying out related exercises.

Session 3: Understanding a variety of problem solving methods, explaining the features of people without problem solving and people with problem-solving ability.

Session 4: Understanding Problem Solving Skills Step One: Defining the exact issue, carrying out activities and exercises with the design of semi-complete stories and intellectual rainfall.

Session 5: Step 2: Provide a list of different solutions, intellectual rainfall and fluid fluidity and practice, providing a half-finished story.

Session 6: Step Three: Assess the solutions and select the best solution, carry out activities and exercises to select the best solutions.

Session 7: Step 4: Assess options and choose the best solution and practice, express the profit and loss of each solution and its consequences. 
Session 8: Step Five: Assessing the implemented solution, Student opinion polls on the effectiveness of the proposed solution.

Session 9: Review the problem solving steps if the solution is not successful, familiar with the concepts of counseling and help from supporters such as family members and teachers and school educators.

Session 10: Review all sessions, encourage the continuation of the exercises and generalize them to life and real life situations, say goodbye and determine the date of the post-test for 3 days later.

\subsection{Method of data analysis}

Data were analyzed using descriptive statistics and Spss21 software. To analyze the descriptive status of the collected data, descriptive statistics such as frequency, percentage, mean and standard deviation were used and inferential statistics of multivariate covariance analysis tests were used.

\section{Conclusion and Discussion}

\section{The first hypothesis:}

Group problem solving training has an impact on social skills in pre-university students.

The results in Table (13-13) and (14-14) indicate the effectiveness of group problem solving training on social skills in pre-college girl students.

In this regard, the research results are consistent with the glorious findings of Yekta et al. (1393). In their research, the group's problem solving training program was effective in increasing social skills and reducing behavioral problems in terms of mothers 'and teachers' grades, and the difference in meanings statistically significant. The results also coincide with the findings of Hamedi Fard (2013), which in his research found that the teaching of social problem solving skills has increased social skills and reduced interpersonal problems; therefore, social skills affected by interaction Social affairs of individuals so that they strengthen social skills and reduce negative behaviors. In other words, on the one hand, the rational expression of thoughts and feelings, the reduction of tension and the improvement of interpersonal communication, and, on the other hand, the consideration of the rights of others and the acquisition of their rights, and ultimately increases the ability to cope with domination and revenge.

\section{The Second hypothesis:}

Group problem solving training has an impact on resilience in pre-college girl students.

The results of (15-15) and (16-16) in the table are indicative of the effectiveness of problem solving problem solving training in pre-college girl students.

The result is consistent with the findings of Atadtekh et al. (2013), which showed that solving social problem solving in promoting resilience and all components of psychological well-being (self-acceptance, positive relationships with others, autonomy, purposeful life and growth Individuals have a positive effect on students with learning disabilities except the component (environmental mastery). Finally, the results of the study coincide with the findings of my colleagues and colleagues (2008), which found that the group problem solving training and social skills of students reduced the extramural behavioral problems.

Facing different problems and problems in life, if accompanied by successful reconciliation and resolution, through the process of strengthening and the revised Thorndike's law, has led to increased self-esteem, selfesteem, sense of efficiency, and increased tolerance people will be Since the variables mentioned are the key characteristics of resiliency and resilient people, it can be concluded that social problem solving training can lead to increased resilience in the student. On the other hand, many studies have shown that there is a relationship between resilience and psychological well-being and quality of life. Therefore, increasing the resilience and promoting the psychological well-being that comes about as a result of solving social problem solving can strengthen each other and ultimately improve the resilience of individuals (Atatokht et al., 2013).

Group problem solving training helps people learn about their surroundings and their environment. Learning this skill increases students' ability to communicate in groups and also strengthens their confidence in gaining information (Dilmaghani, 2003).

\section{The Third hypothesis:}

Group problem solving training has an impact on the social skills of pre-college girl students.

The results presented in Table (2-4) and (22-4) indicate the effectiveness of group problem solving training on the social skills dimensions of pre-college girl students.

In this regard, the research results are consistent with the glorious findings of Yekta et al. (1393). In their research, the group's problem solving training program was effective in increasing social skills and reducing behavioral problems in terms of mothers 'and teachers' grades, and the difference in meanings statistically significant. The results are also consistent with Hamedifard's findings (2013), which showed that teaching social problem solving skills has increased social skills and reduced interpersonal problems; therefore, social skills are affected by social interactions of individuals. In such a way as to boost their social skills and reduce negative behaviors. In other words, on the one hand, the rational expression of thoughts and feelings, the reduction of 
tension and the improvement of interpersonal communication, and, on the other hand, the consideration of the rights of others and the acquisition of their rights, and ultimately increases the ability to cope with domination and revenge.

Research results indicate the positive impact of group problem solving by facilitating communication with friends or developing new relationships. It also solves the spatial problem in which there is no need for the social skills necessary for interpersonal interactions, and this is useful for cornerstone teens. Group-based problem solving training has been said to provide a safe haven to compensate for the lack of social interactions in real life. Group problem solving provides an opportunity for expression, identity, friendship, emotional relationships, and ideological orientation.

\section{The fourth hypothesis:}

Group problem solving education has an impact on the resilience of pre-college girl students.

The results in Table (24-23) and (24-24) indicate the effectiveness of group problem solving training on the resilience dimensions in pre-college girl students.

The results also coincide with the findings of Atadtekh et al. (2013), which showed that solving social problem solving in promoting resilience and all components of psychological well-being (self-acceptance, positive relationships with others, autonomy, purposeful life and individual development ) Has a positive effect on students with learning disabilities, except for the component (environmental mastery).

Execution of problem solving skills leads to special purposeful policies that define people, solve different solutions, make decisions and make a solution. The problem-oriented approach makes people repel their negative emotions, such as anxiety, anger, and depression that prevent the problem from resolving, and forbids the person's tendency to show passive responses. Positive emotions and individual perceptions increase their competence and merit and facilitate problem solving and ultimately empathize with the person to solve their problems and improve the resilience of the students.

\section{References}

Bonanno, G.A., Bucciareli, A., \& Vlahov, D., What predicts psychological resilience after disaster? The role of demographic resources and life stress. Journal of consulting and clinical psychology, 2007, 75(5), 671- 682.

Borba, M. (2001). Building moral intelligence: The seven essential virtues that teach children to do the right thing. USA: Jossey- Bass.

Conner, K. M, \& Davidson, J. R. T. (2003). Development of a new resilience scale: The Conner-Davidson Resilience Scale (CD-RISC). Journal of Depression and Anexiety, 18, pp 76-82.

Garmezy N, Masten, A. The protective role of competence indicators in children at risk. In: Cummings EM, Green AL, Karraki KH, editors. (2001).Life span developmental psychology: Perspectives on stress and coping. Hillsdale, NJ: Lawrence;147-151

Gresham, F. M., Van, M. B., \& Cook, C. R (2006). Social skills training for teaching replacement behaviors: Remediating acquisition deficits in at-risk students. Behavioral Disorders, 3: 363-377.

Keyes, C. M., Shimotkin, D., Ryff, D. D. (2002). "Optimizing well-being: The empirical encounter of two traditions". Journal of Personality and Social Psychology, 82(6), pp: $1002-1022$.

Korinek, L. \&, Popp. A. (2004). Collaborative Mainstream Integration of Social Skills with Academic Instruction. Preventing School Failure, 41(4).148-165.

Loannis, A. \& Efrosini, K. (2008). Nonverbal social interaction skills of children with learning disabilities. Research in developmental disabilities, 29, 1-10.

Matson, J.L., Mayville, S.B., \& Laud, R.B. (2003). A system of assessment for adaptive behavior, social skills, behavioral function, medication side-effects, and psychiatric disorders. Research in Developmental Disabilities, 24, 75-81.

Min, Jung-Ah., Yub, Jeong Jin,. Lee, Chang-Uk., Chaea, Jeong-Ho (2013). Cognitive emotion regulation strategies contributing to resilience in patients with depression and/or anxiety disorders, Comprehensive Psychiatry 54:1190-1197.

Nevid, J. S., \& Rathus, S. A. (2007). Psychology and the challenges of life, 20th Edition. John Wiley \& Sons, Inc

Newman, R., Providing direction on the road to resilience. Behavioral Health Management, 2003, 23(4), $42-43$.

Nezu, A., \& D Zorila, T. J. (2001). Problem-solving training. in kdobsor(edi). Handbook of cognitive behavioral theropice, New York: guiford press.

Robbins B., What is the good life? Positivism and renaissance of humanistic psychology. J Hum Psychol, 2008.36:96-112.

School Girl and Son School Tehran, Tehran, Iran, 2008-8, Master's Thesis, Faculty of Psychology and Educational Sciences, Islamic Azad University, Central Tehran Branch.

Bapiry, Omidali; Bahamin, Ghobad and Faizollahi, Ali (2010). Investigating the Effect of Group-Based Problem-Solving Education on Some Psychological Characteristics of Suicide-Free Adolescents, Scientific 
Journal of Ilam University of Medical Sciences, 18 (1): 16-22.

Bahri, Seyyedeh Leila, Dehghan Manshadi, Marieh and Dehghan Manshadi, Z. (1393). Investigating the Predictability of Resilience and Social Support in Mental Health of Parents of the Deaf and Deaf Children, Exceptional Education Monthly, 14, No. 1, 15-12.

Beneficent, Farshid (1394). The study of the effectiveness of group training of problem solving skills in increasing the social adjustment of male students of Islamic Azad University of Kermanshah, the first scientific conference of psychology, education and community pathology, electronic, green gold company, Pishas Association.

Burgan, Mitra; Enayati, Mirsalladdin; Mehrabizadeh Armanand, Mahnaz (2008). Effectiveness of problem solving problem solving training on general health and marital satisfaction of spouses of male employees of the satellite program, new findings in psychology (social psychology), 2 (7): 95-107.

Bahmanzadegan Jahromi, Marzieh (2010). The Effectiveness of Social Skills Training through Social Stories on Autistic Behaviors and Social Development of Children with Autism in Shiraz, Master's Thesis, Isfahan University.

Poursardar, Fayyasal; Abbaspour, Zabihollah; Abdi Zarrin, Sohrab and Sangiberi Ali Akbar (2012). The effect of resilience on mental health and life satisfaction, a psychological pattern of well-being. Found 14 (1): 81 89.

Tarzifi, Mahdiyeh (1391). Resilience and the role of advisors, Journal of School Advisor Development, 7 (2): 12-15.

Wielding, Leila; Yazd Hawasseni, Fariba, Abedi, Ahmad (1392). Effect of computer-based listening exercises on the sustained attention of children with attention deficit / hyperactivity disorder. Journal of Behavioral Sciences, 11 (6): 532-544.

Jafari, Fatemeh (1391). Factors Affecting Students' Questioning in Class. Book of the Moon of Social Science, 16th year, 55 (157): 101-104. 